\title{
Observation of Multiple Pulse-Splitting of Ultrashort Pulses in Air
}

\author{
A.C. Bernstein ${ }^{\dagger \S}$, T.S. Luk ${ }^{\dagger}$, T.R. Nelson ${ }^{\dagger}$, J.-C. Diels ${ }^{\S}$ and S. Cameron ${ }^{\dagger}$ \\ tSandia National Laboratories, P.O. Box 5800, Albuquerque, NM 87185 \\ \$Physics and Astronomy Department, University of New Mexico, 800 Yale Blvd. NE, Albuquerque NM, 87131 \\ (505) 284-5699, acberns@sandia.gov
}

\begin{abstract}
We present experimental data on multiple-pulse-splitting of ultrashort pulse propagation in air. Pulse splitting occurs before spatial collapse to a filament. The threshold power for pulse splitting is $7 \mathrm{GW}$ for a $315 \mathrm{fs}$ chirped pulses at $800 \mathrm{~nm}$. (C) 2000 Optical Society of America

OCIS codes: (190.7110) Ultrafast nonlinear optics; (320.2250) Self-focusing
\end{abstract}

\section{Introduction}

It has been shown in $3+1$ dimensional Kerr-nonlinearity self-focusing models, that group velocity dispersion [1] is responsible for the temporal pulse-splitting of ultrashort pulses during propagation [1]. Previous experiments have demonstrated pulse splitting due to the Kerr nonlinearity for short pulse propagation in bulk [2] or gaseous media [3]. However, studies in gaseous media are often in a focused geometry, and use pressurized gaseous media [4]. This experiment elucidates the relationship between pulse splitting and spot-size change and does not use any optic to initiate self-focusing [4]. We find pulse splitting occurs at a distance merely $0.7 \mathrm{x}$ the diffraction length and occurs before spatial collapse to a filament. In addition, multiple pulse splitting is also observed. Peak fluence information from the beamprofile is monitored, indicating nonlinear loss mechanisms. We believe this is the first data on multiple pulse-splitting events in air.

\section{Experimental Setup}

Our pulses are produced with a chirped-pulse amplification Ti:Sapphire laser system capable of delivering $150 \mathrm{GW}$ of power after compression. For these experiments, the system is run at $<25 \mathrm{GW}$ (200fs-1ps, $1-$ $5 \mathrm{~mJ}$ ). Before entering the compressor, the beam passes through a $4 \mathrm{~mm}$-diameter soft fused silica apodizing aperture, imposing a near-Gaussian profile on the beam. One meter after leaving the compressor, a beamsplitter transmits $5 \%$ of the beam for energy measurement and reflects the remainder for propagation down a $10 \mathrm{~m}$ path. A CCD camera images the spatial profile of the beam incident on an alumina-plate screen. The brightest pixel from each image is recorded as a measure of the peak fluence (time integrated intensity) of the beam. For data presented here, we monitor the peak fluence, spatial profile and temporal pulse profile of a $315 \mathrm{fs}$ pulse, with a single-short second harmonic autocorrelator at a distance $11 \mathrm{~m}$ from the compressor as the incident energy is varied.

\section{Results}

Figure 1 shows the peak fluence vs. pulse energy. The onset of self-focusing is evident in the region $A-C$ in Fig. 1 as the peak fluence increases nonlinearly with laser energy. However, even up to energies of $4 \mathrm{~mJ}$, a fully collapsed filament is not observed. Interestingly, there are two plateau regions beginning at 2.5 and $3.6 \mathrm{~mJ}$. Although we do not yet fully understand these regions, we speculate that some nonlinear absorption processes take place during propagation or on the alumina surface. The corresponding autocorrelation traces for the locations $\mathrm{A}-\mathrm{F}$ in Fig.1 are shown in Fig. 2. The onset of pulse splitting is evident by the three-peak autocorrelation trace at location $C$ when the peak power is $7 \mathrm{GW}$, which is sustained through location E. Further splitting occurs at location $F$ when the incident laser energy is $4 \mathrm{~mJ}$. Correlating the temporal change with the spatial profile, there is a progressive shrinkage of beam waist. At the point when the pulse splits, the beam diameter is only $\sim 40 \%$ of its original size, far from total collapse. Numerical simulations by Bouma [5] have shown that pulse splitting and spatial collapse occur at the same time. The difference may be due to the initial chirp condition of the pulse in the experiment. 


\section{DISCLAIMER}

This report was prepared as an account of work sponsored by an agency of the United States Government. Neither the United States Government nor any agency thereof, nor any of their employees, make any warranty, express or implied, or assumes any legal liability or responsibility for the accuracy, completeness, or usefulness of any information, apparatus, product, or process disclosed, or represents that its use would not infringe privately owned rights. Reference herein to any specific commercial product, process, or service by trade name, trademark, manufacturer, or otherwise does not necessarily constitute or imply its endorsement, recommendation, or favoring by the United States Government or any agency thereof. The views and opinions of authors expressed herein do not necessarily state or reflect those of the United States Government or any agency thereof. 


\section{DISCLAIMER}

Portions of this document may be illegible in electronic image products. Images are produced from the best available original document. 


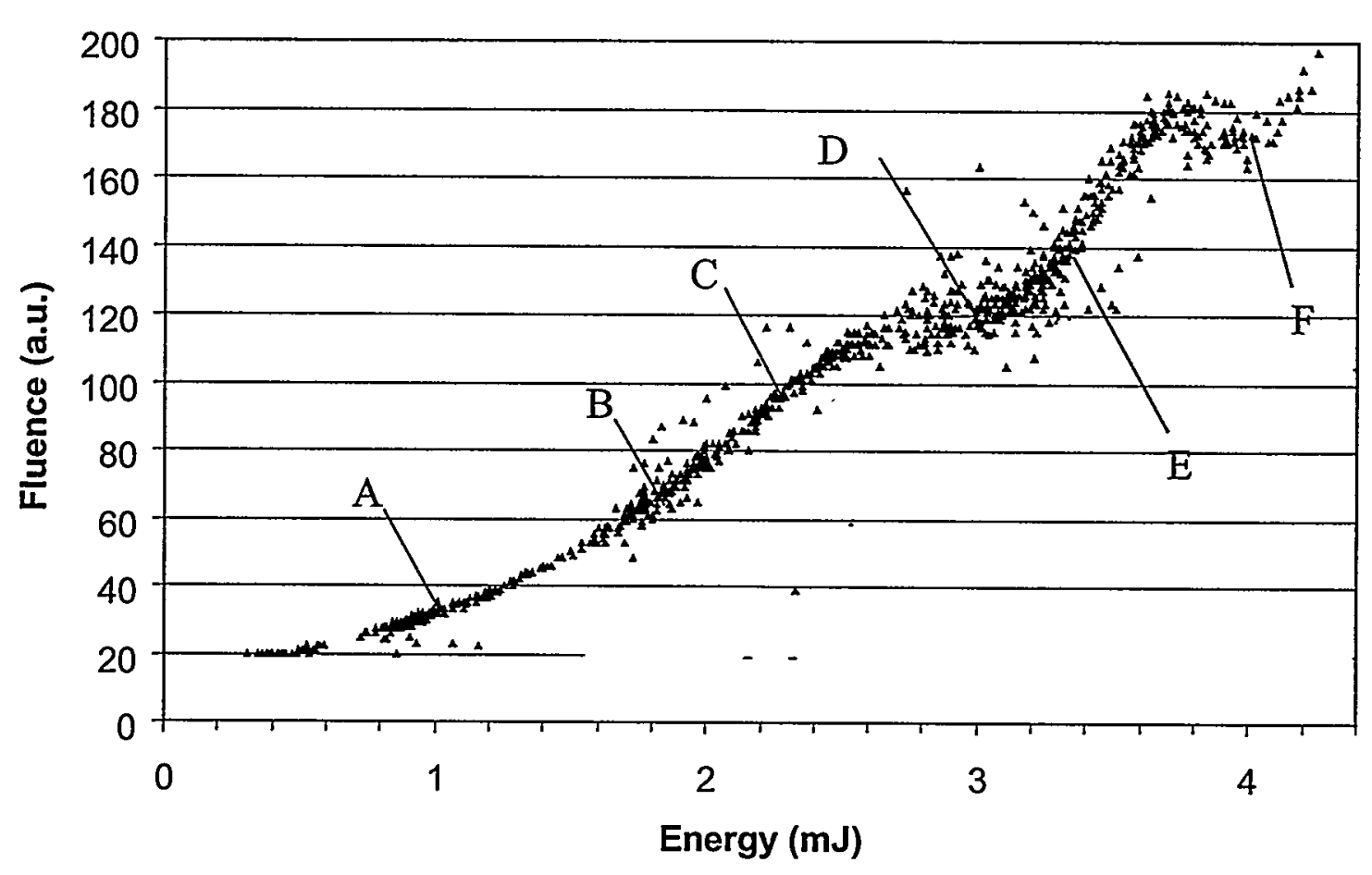

Figure 1. Data for $11 \mathrm{~m}$ with labels corresponding to autocorrelation traces (see Figure 2) at their recorded energies.
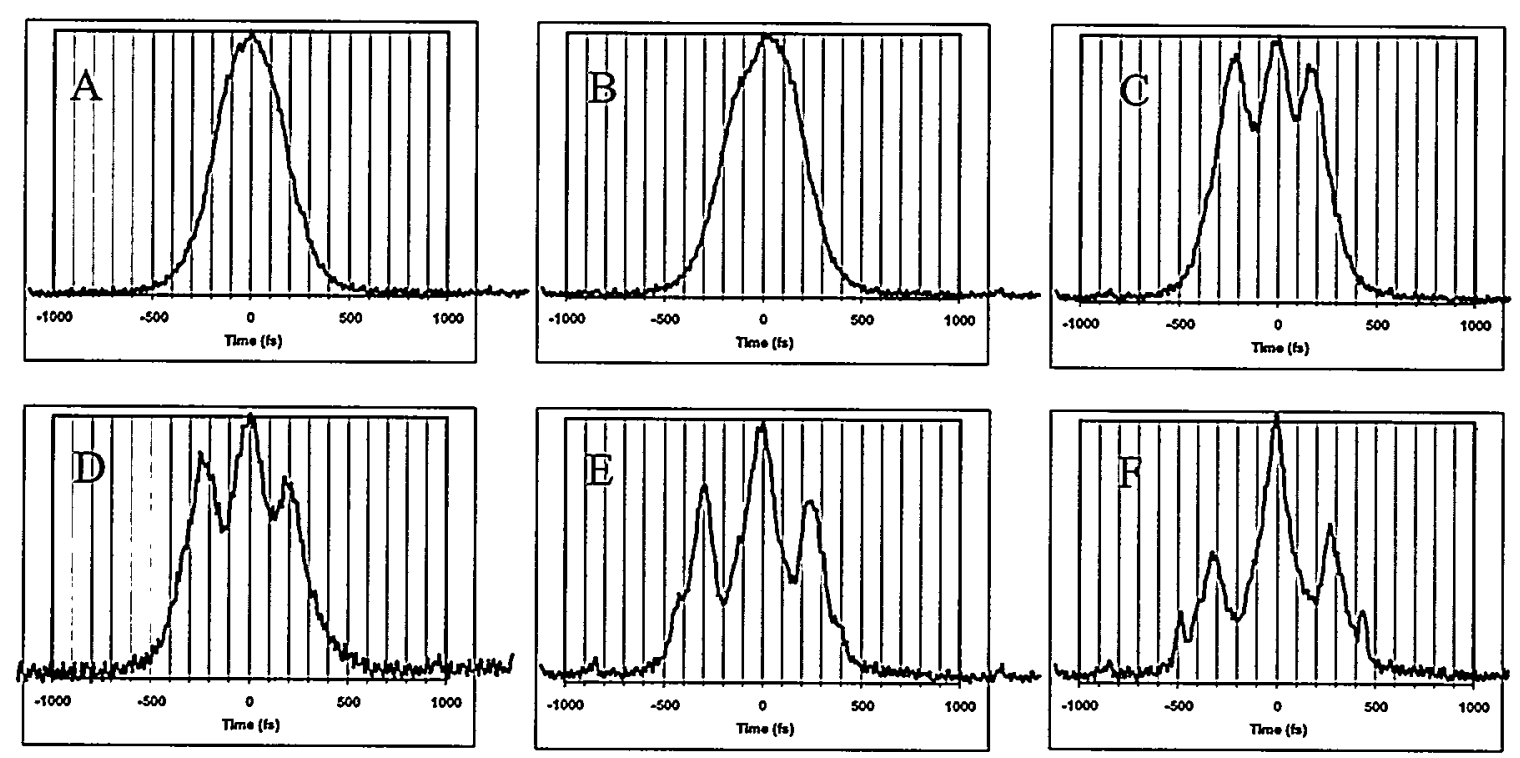

Fig. 2 Autocorrelation traces corresponding to labeled positions in Figure 1. Pulse splitting initiates at point $\mathrm{C}$ in Figure $1(C)$. The pulse remains split in this manner until point $E$, where shoulders appear indicating a third pulse. The split into three pulses is clearly shown in F. The autocorrelation traces are not normalized to the intensity profile.

\section{Acknowledgements:}

Sandia is a multi-program laboratory operated by Sandia Corporation, a Lockheed Martin Company, for the United States Department of Energy under Contract DE-AC04-94AL85000. 


\section{References:}

[1] J.E. Rothenberg, "Pulse splitting during self-focusing in normally dispersive media", Opt. Lett. 17, 583, 1992.

[2] J.K. Ranka, R. W. Schirmer, A. L. Gaeta, "Observation of pulse splitting in nonlinear dispersive media," Phys. Rev. Lett. 77 3783, 1996

[3] I.G. Koprinkov, A. Suda, P. Wang, K. Midorikawa, "Self-Compression of high -intensity femtosecond optical pulses and spatiotemporal soliton generation" Phys. Rev. Lett. 84 3847, 2000

[4] A. Talebpour, S. Petit, S.L. Chin, "Re-focusing during the propagation of a focused femtosecond Ti:Sapphire laser pulse in air," Optics Comm. 171 285, 1999

[5] B.E. Bouma. "Generation and self-phase modulation of ultrashort laser pulses". Ph.D. Thesis, 1993. 